This item was submitted to Loughborough's Research Repository by the author.

Items in Figshare are protected by copyright, with all rights reserved, unless otherwise indicated.

\title{
Pigment mixing effect realized with pre-dyed opaque yarns for Jacquard textile design development
}

PLEASE CITE THE PUBLISHED VERSION

https://doi.org/10.1177/0040517517741153

PUBLISHER

SAGE Publications $@$ The Authors

VERSION

AM (Accepted Manuscript)

\section{PUBLISHER STATEMENT}

This work is made available according to the conditions of the Creative Commons Attribution-NonCommercialNoDerivatives 4.0 International (CC BY-NC-ND 4.0) licence. Full details of this licence are available at: https://creativecommons.org/licenses/by-nc-nd/4.0/

\section{LICENCE}

CC BY-NC-ND 4.0

\section{REPOSITORY RECORD}

Kim, Ken Ri, Frankie Man Ching Ng, Jiu Zhou, and Jinlian Hu. 2017. "Pigment Mixing Effect Realized with Predyed Opaque Yarns for Jacquard Textile Design Development”. Loughborough University. https://hdl.handle.net/2134/27570. 


\title{
Pigment mixing effect realised with pre-dyed opaque yarns for Jacquard textile design development
}

\begin{abstract}
In modern Jacquard weaving, the application of yarn colour variety is limited to electronic Jacquard machinery and realizing a wide scope of weave colours can be challenging. Therefore, when reproducing a pictorial image with a small yarn variety, artwork colours are defined by a CMYK (Cyan, Magenta, Yellow and Black) system and its primary colour data are used to associate with weave structures. In alignment with a CMYK pattern layout, shaded weave structures are incorporated to expand the accessible gamut of weave colours and natural shading is realised by different cover factors in the warp and weft. The mixing effect of CMYK yarns is intended for resolving the technical limitations of current digital Jacquard weaving. In this study, quantitative research is designed to examine four yarn mixing effects for which pairs of CMYK yarns are superimposed (e.g. $[\mathrm{C}]+[\mathrm{M}],[\mathrm{C}]+[\mathrm{Y}]$, $[\mathrm{M}]+[\mathrm{Y}],[\mathrm{C}]+[\mathrm{K}],[\mathrm{M}]+[\mathrm{K}],[\mathrm{Y}]+[\mathrm{K}])$ and ninety different weave colours are produced in six groups. Once they are formatted in a standardised size, weave samples are measured by a spectrophotometer and analysed by three coordinates $\left(\mathrm{L}^{*}, \mathrm{a}^{*}\right.$ and $\left.\mathrm{b}^{*}\right)$ of a CIELAB colour system. As shown by the analysis results, the weave colours bear not only varied brightness, hue and chroma alternations but also a great similarity to the pigment mixing effect. In application of the colour mixing effect, a new way of woven colour presentation is achieved and introduced as a new development of Jacquard design.
\end{abstract}

Keyword: pigment mixing effect, weave colour gamut enlargement, CMYK yarn mixing effect, gradient colour deviation. 


\section{Introduction}

Modern digital weaving has focused on efficiency and convenience of production. The warp is set in a continuous style and the application of filling yarn is limited to electronic Jacquard machinery ${ }^{1}$. In order to expand the gamut of weave colours with a small weft variety, the CMYK colour system is widely used to define artwork colours and its four primary colour data (i.e. cyan, magenta, yellow and black) are applied to multiplication of colour reproduction ${ }^{2}$. In CMYK-based weave pattern, weft colours are aligned with the four primaries $(\mathrm{CMYK})$ and their floats are organised by shaded weave structure ${ }^{3,4}$. The colour mixing effect, however, has not been closely examined for gamut expansion. To focus on brightness, hue and chroma alternations, ninety weave colours are produced and inspected in an attempt to overcome the limitations of current digital Jacquard weaving. For six groups (i.e. $[\mathrm{C}]+[\mathrm{M}],[\mathrm{C}]+[\mathrm{Y}],[\mathrm{M}]+[\mathrm{Y}],[\mathrm{C}]+[\mathrm{K}],[\mathrm{M}]+[\mathrm{K}],[\mathrm{Y}]+[\mathrm{K}]$ ) of actual weave colour production, 16-thread sateen weave is created into a series of shaded weave structures and two different sets are built for even distribution of filling yarn floats ${ }^{5}$. Each pair produces 15 different shades with dissimilar cover factors in the warp and weft. Once all the weave samples are formatted in a standardised size (i.e. $6 \mathrm{~cm} \times 6 \mathrm{~cm}$ ), they are all measured by a Macbath colour-eye 7000A spectrophotometer.

CIELAB (i.e. Commission Internationale de l'Eclairage $\mathrm{L}^{*} \mathrm{a} * \mathrm{~b} *$ ) space can describe all colours that a human visual system can perceive. Colours are defined by $\mathrm{L}^{*}, \mathrm{a}^{*}$ and $\mathrm{b}^{*}$ coordinates of CIELAB data, where $\mathrm{L}^{*}$ signifies a visual correlation of brightness from 0 (i.e. black) to 100 (i.e. pure white) and $a^{*}$ and $b^{*}$ represent positive (+) and negative (-) values (e.g. $+a^{*}$ (redness), $-a^{*}$ (greenness), $+b^{*}$ (yellowness) and $-b^{*}$ (blueness)) to describe hue and chroma ${ }^{6}$. When the $a^{*} b^{*}$ values of pair combinations draw an arch line (Figure $1-(a)$ ) 
along with the $\pm a^{*} b^{*}$ values, hue alternations are indicated. Whilst a straight line (Figure 1(b)) is drawn from centre to outward of the $a^{*}$ or $b^{*}$ axis, chroma alterations are denoted. If an $\mathrm{L}^{*}$ value (Figure $1-(\mathrm{c})$ ) is close to 0 , colour is nearing black; however, if a value approaches 100 , colour is viewed as bright as white ${ }^{6}$. In this study, the three coordinates of CIELAB are used to analyse the yarn colour mixing effect. The measured colour values of yarn and weave swatches are presented in graphs (Figures 2, 4, 6, and 8) and its raw data (Tables 4, 5, 6 and 7) in the appendix.

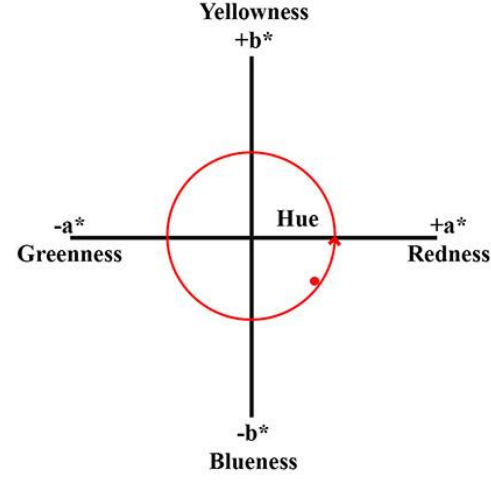

(a)

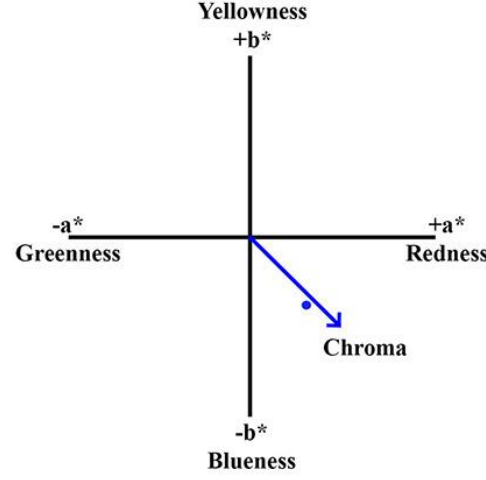

(b)

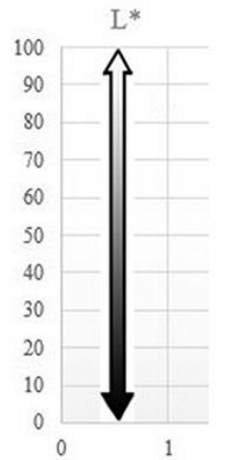

(c)

Figure 1. Colour description based on (a) hue, (b) chroma and (c) brightness (Berns et al., $2000^{6}$ )

Based on the results of the weave colour examination, the capability to conceive consistent brightness, hue and chroma alternations is confirmed when the juxtaposed yarn colour is presented in great similarity to the pigment mixing effect. Although materials used for colour creation are non-transparent and non-blendable, the four types of colour yarns are capable of generating their secondary colour ranges via natural shading. When developing a new way of displaying woven colours, further modifications are applied to weave patterns. In this study, the detailed process from the evaluation of the four yarn colours to the development of novel Jacquard design is introduced and explained. 


\section{Materials and Research Methods}

\section{Selection and measurement of filling yarn colours}

In the preparation of filling yarns, simple multifilament polyester yarn is selected to identically align with the fixed warp property. When selecting pre-dyed yarns, the saturated CMYK colours are created in CMYK mode with Photoshop CS6. As it is difficult to possess $100 \%$ saturated cyan, magenta, yellow and black in yarns, the screen colours are referenced for weft selection to be similar to CMYK. In the shaded weave structure layout, the CMYK yarns are examined to discover their mixing principles and the capability to expand the gamut of weave colours rather than match colours or define colour differences.
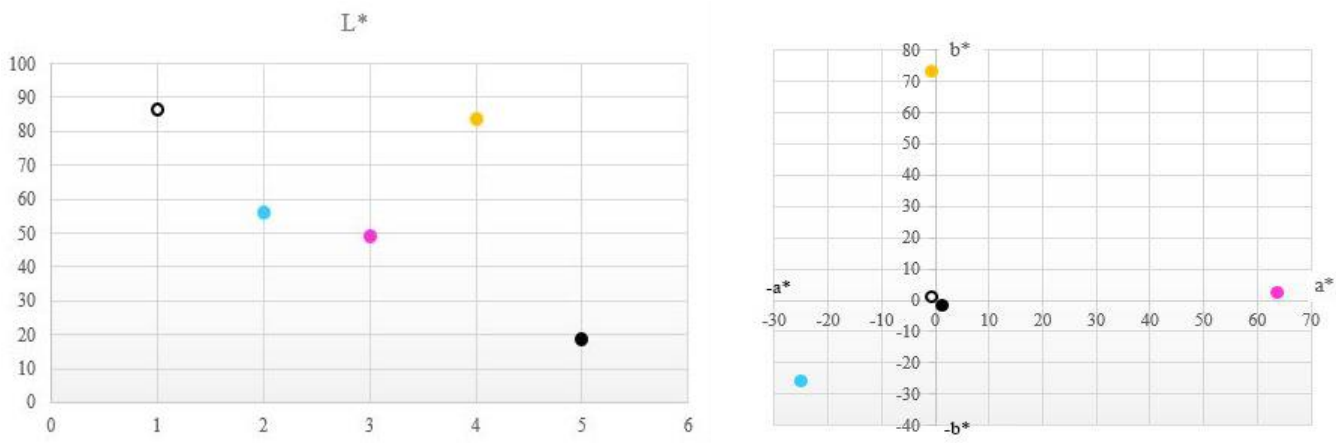

Figure 2. Measured warp and filling yarn colours in $\mathrm{L}^{*}$ and $\mathrm{a}^{*} \mathrm{~b}^{*}$ values

Four filling yarns and warp threads are wound in four layers onto a non-fluorescent black cardboard and measured by the Macbath colour-eye 7000A spectrophotometer. The measurement conditions applied to yarn and weave samples are illuminant D65, diffuse $/ 8^{\circ}$ geometry, $10^{\circ}$ supplemental standard observer, specular component included, large area view, and UV excluded. Figure 2 shows that the L* values of each yarn group lie between 90 and 20 while the off-white warp is positioned in the highest (86.49) and the black weft the lowest (18.74). In terms of the $a^{*} b^{*}$ values, cyan, magenta and yellow yarns are defined according to 
their possession of blueness, greenness, redness and yellowness, respectively.

\section{Plan and method of weave colour sampling}

Based on the 16-thread sateen weave structure, two different weave sets are created by applying different starting points and step movements (Figure 3) ${ }^{7}$. In each set, four interlacements are applied every time until a 16-thread sateen weave repeat is built into a series by which 53 single-shaded weaves are created to generate different levels of shades. However, as each single-shaded weave is transformed with a slight increase in interlacement, 8 weave structures are selected from each set to retain a certain level of colour variation. The details of weave structure combination are shown in Figure 3.

\begin{tabular}{|c|c|c|c|c|c|c|c|c|c|c|c|c|c|c|c|}
\hline No & & 2 & 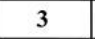 & 4 & 5 & & & & & 10 & 11 & 12 & 13 & 14 & 15 \\
\hline $\begin{array}{r}\text { 1st wea } \\
\text { weft/war }\end{array}$ & /80 & $30 / 70$ & $41 / 59$ & $\mathbf{5 0 / 5 0}$ & $60 / 40$ & $70 / 30$ & $80 / 20$ & $91 / 9$ & 91/9 & 91/9 & 91/9 & 91/9 & 91/9 & 91/9 & $91 / 9$ \\
\hline & & & 31 & 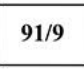 & 31 & & & & $80 / 20$ & $70 / 3$ & $60 / 40$ & $\mathbf{5 0 / 5 0}$ & $41 / 59$ & & \\
\hline & & & 돈 & $F$ & $\vec{E}$ & $\underline{\overline{ }}=$ & & & & & & & & & \\
\hline & & & & & & & & & & $\begin{array}{l}\equiv \equiv \\
\equiv=\end{array}$ & $\sum$ & 풀 & 두ㄹㅜㅜ룰 & & \\
\hline $\begin{array}{l}\text { Compound } \\
\text { Weave }\end{array}$ & 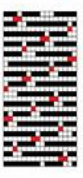 & 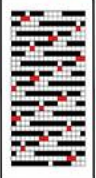 & 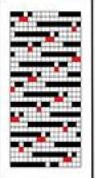 & $\begin{array}{l}=5 \\
=3\end{array}$ & $\begin{array}{l}== \\
== \\
=2\end{array}$ & $\begin{array}{l}-= \\
-= \\
-\div= \\
-1\end{array}$ & 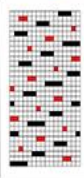 & $\begin{array}{l}\because \because 3 \\
\because \because \vdots \\
\because \because \vdots \\
\because \because\end{array}$ & $\begin{array}{l}=\div: \\
\vdots \vdots \\
\div \div \\
\div \div\end{array}$ & $\begin{array}{l}-\frac{3}{\div} \div \\
\div \div \div \\
\div \div\end{array}$ & $\begin{array}{l}\div \div \\
\div \div= \\
\div \div \\
\div-2\end{array}$ & $\begin{array}{l}54 \\
25 \\
24\end{array}$ & $\begin{array}{l}\frac{x}{2 x} \\
\frac{2 x}{2 x} \\
\frac{2 x}{x-2}\end{array}$ & $\begin{array}{l}\frac{2 x}{x-2} \\
x=3 \\
x=3\end{array}$ & $\begin{array}{ll}x e \\
x e\end{array}$ \\
\hline
\end{tabular}

Figure 3. Combination plan of single-shaded weave structure for prototype creation

Weave 8 (Figure 3 ) has an equal portion of weft cover factors as given in both the $1^{\text {st }}$ weave and $2^{\text {nd }}$ weave, either of which is fixed or declined by their shares of colour exhibiting on the surface. For example, the cover factor in the warp and weft gradually decreases in the first weave series (e.g. from $91 \%$ to $20 \%$ of the total interweaving points), while the second series has a fixed proportion of 91/9 (weft/warp), and vice versa. Therefore, when two colour yarns are combined, the $2^{\text {nd }}$ weave dominates the surface in compound weaves $1-8$ and the $1^{\text {st }}$ 
weave does so in compound weaves 8-15.

The Arahne Jacquard CAD system is employed to combine single weave structures (Figure 3). In the extra weft mode, a weaving file is created in compatible format for the Jacquard machine (Stäubli JC6). Using fine yarn in the weft is found to be advantageous for natural colour presentation in a high density. Therefore, 50-denier polyester yarn is supplied as the weft to interweave with the 100-denier off-white polyester warp. The weaving specifications applied to sample production are shown in Table 1 below.

Table 1. Weaving specifications for prototype creation

\begin{tabular}{|c|c|c|}
\hline Composition & Weft & Warp \\
\hline Material & $100 \%$ polyester & $100 \%$ polyester \\
\hline Thread colour & Magenta/cyan/yellow/black & Off-white \\
\hline Yarn count & 50 denier & 100 denier \\
\hline Yarn type & Multifilament & Multifilament \\
\hline $\mathbf{2}$ colour filling density & 512 picks/10cm & 472 ends/10cm \\
\hline Jacquard machine & \multicolumn{2}{|c|}{ Stäubli JC6 } \\
\hline Total hooks & \multicolumn{2}{|c|}{8192} \\
\hline Pattern repeat & 289 cm (width) x 10 cm (height) \\
\hline Weave repeat & 16 -thread sateen weave \\
\hline Shaded weave variety & \multicolumn{2}{|c|}{53} \\
\hline Software applied & \multicolumn{2}{|c|}{ Arahne CAD } \\
\hline
\end{tabular}

\section{Results and Discussion}

\section{Evaluaion of weave colours proposed by four primary colour yarns of CMYK system}

In the course of analysing the weave colour data, results are validated to propose the yarn colour mixing principle for weave colour gamut expansion. For standardised measurement, six groups (i.e. $[\mathrm{C}]+[\mathrm{M}],[\mathrm{C}]+[\mathrm{Y}],[\mathrm{M}]+[\mathrm{Y}],[\mathrm{C}]+[\mathrm{K}],[\mathrm{M}]+[\mathrm{K}],[\mathrm{Y}]+[\mathrm{K}]$ ) of CMYK pairs are formatted in one size (i.e. $6 \mathrm{~cm} \times 6 \mathrm{~cm}$ ) and made into two folded layer samples to ensure that no light passes through interwoven slits. Ninety samples of six groups are measured by the 
Macbath colour-eye 7000A spectrophotometer in the same measurement conditions applied to the yarn colour inspection. Through the $a^{*} b^{*}$ values of CIELAB, individual weave colours are defined in a hue-and-chroma relation while the $\mathrm{L}^{*}$ values of the six groups are measured and presented from 0 (black) to 100 (white) for specifying the brightness of each colour.

Figure 4 shows that the $L^{*}$ values of the six group mixtures lie between $L^{*}=30-80$. In the yarn colour measurement (Figure 2), yellow is presented as the brightest (83.52) among the four filling yarns. Therefore, when it is mixed and surrounded with cyan and magenta, the $\mathrm{L}^{*}$ values of the two groups (e.g. $[\mathrm{C}]+[\mathrm{Y}],[\mathrm{M}]+[\mathrm{Y}]$ ) become even brighter than the individual $\mathrm{L}^{*}$ values of cyan and magenta yarn as the exhibited yellow yarn reflects more light in its combination (Figure 4). In contrast, the groups (e.g. $[\mathrm{C}]+[\mathrm{K}],[\mathrm{M}]+[\mathrm{K}]$ and $[\mathrm{Y}]+[\mathrm{K}]$ ) involving black (18.74) become less bright as the exhibited black is surrounded and the weave colour absorbs more light from the surface. As a result, the brightness of the yarn colours mixed through the shaded weave structure is gradually altered and influenced by their surroundings (Figure 4).

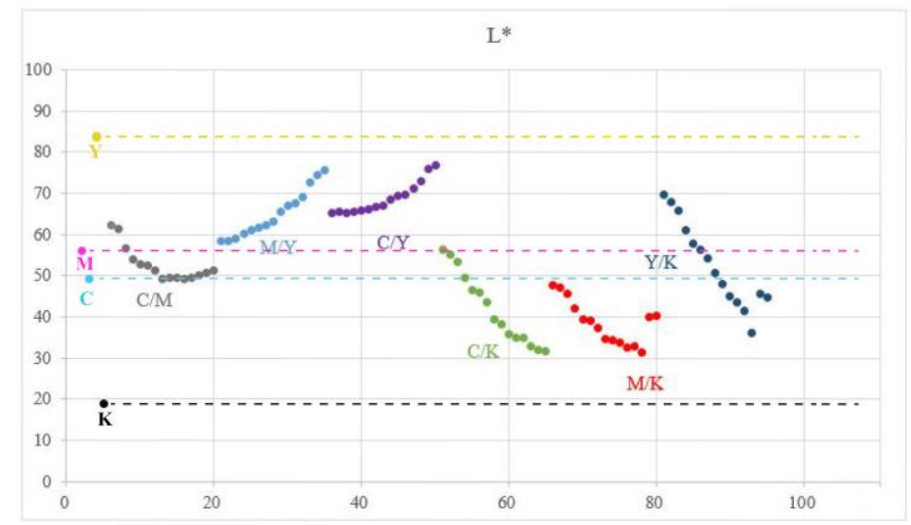

Figure 4. L* values of six groups of CMYK samples

In relation to hues, the three groups (i.e. $[\mathrm{C}]+[\mathrm{Y}],[\mathrm{C}]+[\mathrm{M}]$ and $[\mathrm{M}]+[\mathrm{Y}]$ ) of yarn juxtaposition (Figure 5) show valid results for potential expansion of weave colours. As it is 
evidenced by the $a^{*} b^{*}$ values of weave colour data in Figure 6, the weave colours comprising small particles of two yarn colours are capable of creating their secondary colour ranges via natural shading. For instance, when cyan and yellow yarns are mixed by different cover factors in the warp and weft, 15 resultant shades are positioned and lined up between the two yarn colours used for their creation. The two juxtaposed opaque colour yarns create a natural pigment mixing effect through delicate management of interlacements.

\begin{tabular}{|c|c|c|c|c|c|c|c|c|c|c|c|c|c|c|c|}
\hline No & 1 & 2 & 3 & 4 & 5 & 6 & 7 & 8 & 9 & 10 & 11 & 12 & 13 & 14 & 15 \\
\hline $\begin{array}{c}\text { 1st weave } \\
\text { weft/warp \% }\end{array}$ & $20 / 80$ & $30 / 70$ & 41/59 & $50 / 50$ & $60 / 40$ & $70 / 30$ & $80 / 20$ & 91/9 & $91 / 9$ & $91 / 9$ & $91 / 9$ & $91 / 9$ & $91 / 9$ & $91 / 9$ & $91 / 9$ \\
\hline $\begin{array}{c}\text { 2nd weave } \\
\text { weft/warp \% }\end{array}$ & $91 / 9$ & $91 / 9$ & $91 / 9$ & $91 / 9$ & $91 / 9$ & $91 / 9$ & $91 / 9$ & $91 / 9$ & $80 / 20$ & $70 / 30$ & $60 / 40$ & $50 / 50$ & $41 / 59$ & $30 / 70$ & $20 / 80$ \\
\hline Magenta/Yellow & & & & & & & & & & & & & & & \\
\hline Cyan/Yellow & & & & & & & & & & & & & & & \\
\hline
\end{tabular}

Figure 5. Actual weave colour samples of $\mathrm{C} / \mathrm{M}, \mathrm{M} / \mathrm{Y}$ and $\mathrm{C} / \mathrm{Y}$

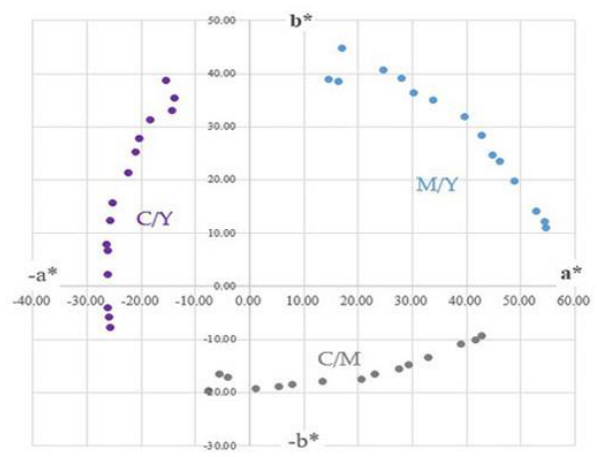

(a)

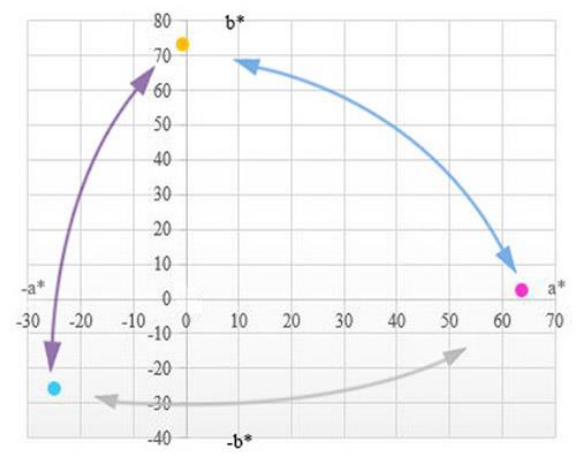

(b)

Figure 6. (a) measured $a^{*} b^{*}$ colour values of $C / Y, C / M$ and $M / Y$ created from the $C M Y$ yarns (b)

With regard to the groups mixed with black (i.e. $[\mathrm{Y}]+[\mathrm{K}],[\mathrm{M}]+[\mathrm{K}]$ and $[\mathrm{C}]+[\mathrm{K}]$ ) (Figure 7 ), straight lines are drawn from centre to outward of the $a^{*}$ and $b^{*}$ axes (Figure 8). When the primary CMY colour yarns are mixed with black which does not involve hue or chroma and 
stays in the centre of the $a^{*} b^{*}$ axes, the resultant weave colour data created through the shaded weave structure show that the chroma levels of weave colours can be controlled. By decreasing or increasing the cover factor in black on the surface, the chroma levels of cyan, magenta and yellow change gradually.

\begin{tabular}{|c|c|c|c|c|c|c|c|c|c|c|c|c|c|c|c|}
\hline No & 1 & 2 & 3 & 4 & 5 & 6 & 7 & 8 & 9 & 10 & 11 & 12 & 13 & 14 & 15 \\
\hline $\begin{array}{c}\text { 1st weave } \\
\text { weft/warp \% }\end{array}$ & $20 / 80$ & $30 / 70$ & $41 / 59$ & $50 / 50$ & $60 / 40$ & $70 / 30$ & $80 / 20$ & $91 / 9$ & 91/9 & $91 / 9$ & $91 / 9$ & $91 / 9$ & $91 / 9$ & $91 / 9$ & $91 / 9$ \\
\hline $\begin{array}{c}\text { 2nd weave } \\
\text { weft/warp \% }\end{array}$ & $91 / 9$ & 91/9 & $91 / 9$ & $91 / 9$ & 91/9 & $91 / 9$ & $91 / 9$ & 91/9 & $80 / 20$ & $70 / 30$ & $60 / 40$ & $\mathbf{5 0} / \mathbf{5 0}$ & 41/59 & $30 / 70$ & $20 / 80$ \\
\hline Magenta/Black(K) & & & & & & & & & & & & & & & \\
\hline & & & & & & & & & & & & & & & \\
\hline
\end{tabular}

Figure 7. Actual weave colour samples of $\mathrm{C} / \mathrm{K}, \mathrm{M} / \mathrm{K}$ and $\mathrm{Y} / \mathrm{K}$

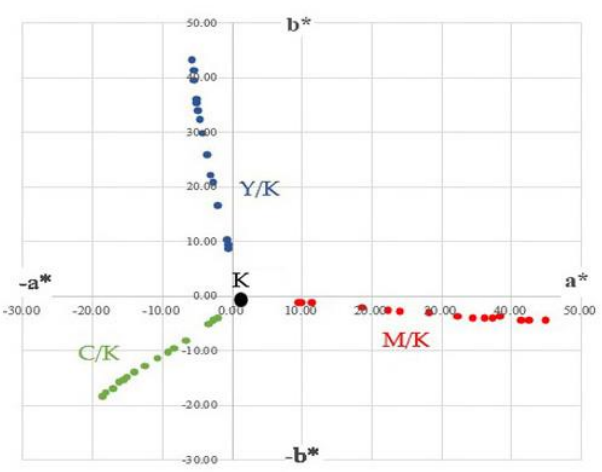

(a)

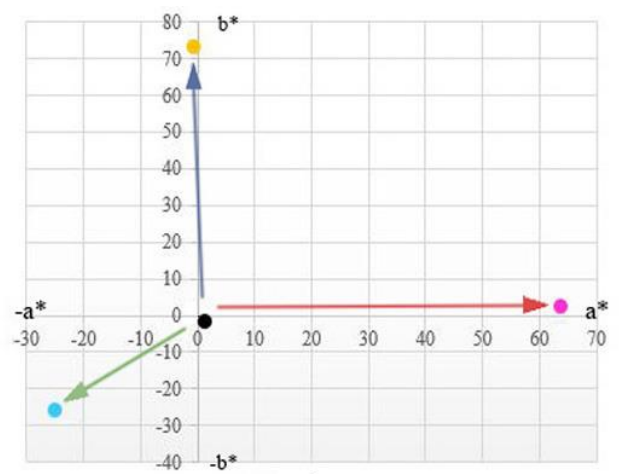

(b)

Figure 8. (a) measured $a^{*} b^{*}$ colour values of $C / K, M / K$ and $Y / K$ created from the CMYK yarns (b)

In the examination of the CMYK mixing effect, constant hue and chroma alternations are highly reliable via shaded weave structures. The pairs of CMY yarn combinations are capable of presenting their secondary colours as the pairs of CMY pigments are blended into each other. On the other hand, when the CMY combinations are mixed with black yarn, their chroma levels are varied and controlled. Based on the results, the employment of CMYK 
colours in filling groups is suggested for reducing the limitations of modern weaving. Additionally, the weave colours realised in this layout will be further explored for the new development of digital Jacquard design.

\section{Application of yarn colour mixing effect for development of new digital Jacquard design}

\section{Preliminary experimentation - Weave structure and weave pattern design}

For a deeper understanding of the colour mixing effect, the creation of weave colours is further experimented to develop new digital Jacquard design. In order to realise a wide scope of weave colours with a limited colour variety, the shaded weave format is used to offer varied tones and hues. When creating shaded weave series, a small number of interlacements are used to generate natural shades and two sets are built for distributing filling yarns evenly on the surface ${ }^{8}$. As the simplest model used to define the substrates of respective colourful images is essentially a 'grey-scale' ${ }^{9}$, motif colours are designed in the greyscale mode in which the greyscale variety from 0 to 255 is reduced according to a total shaded weave variety so as to make one-to-one corresponding between shaded weave variety and greyscale 10

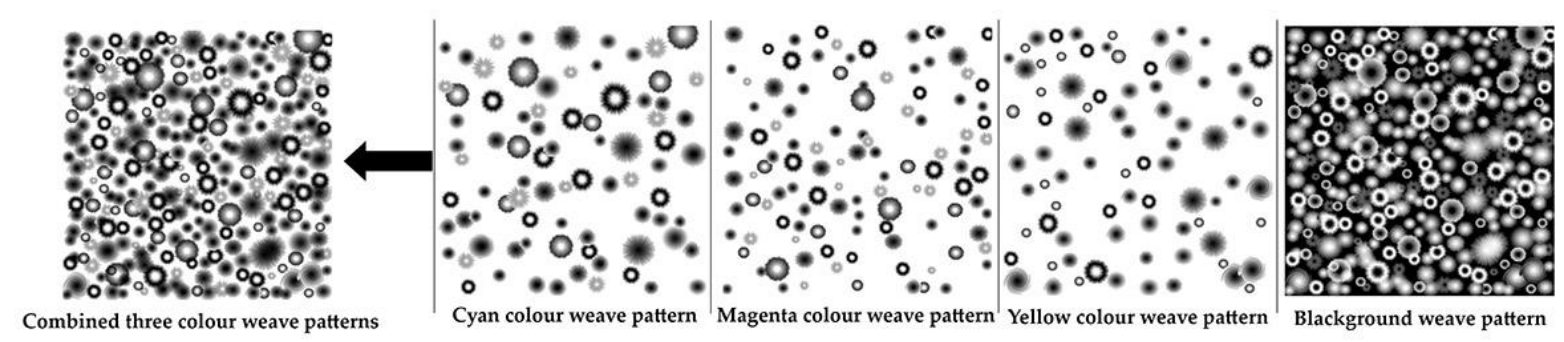

Figure 9. Weave pattern design to inspect embracement of pigment mixing effect

For developing new digital Jacquard design, preliminary experimentation is conducted. Weave structures and weave patterns are designed to test when cyan, magenta and yellow 
yarns are overlaid through motifs. The full series of 16-thread sateen-shaded weaves applied to yarn colour examination is used in this experiment. As shown in Figure 9, the three colour patterns of floral motifs (i.e. cyan, magenta and yellow) and the background (white) are designed in a continuous tone of greyscale. In this condition, the filling yarns of the first and second shaded weave series are overlaid in their gradual length growths (Figure 10) and yarn colours are displayed in seamless shading.

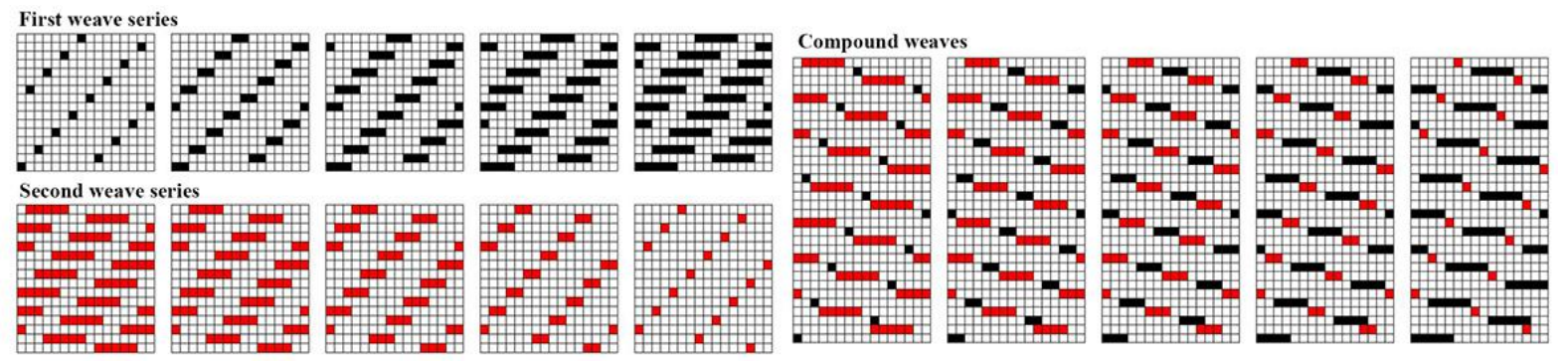

Figure 10. Shaded weave structure layout for simulating pigment mixing effect

In alignment with shaded weaves and greyscale patterns, the three filling yarns are floated and interwoven with the warp. Figure 11 shows that the colour mixing effect is realised through the floral motifs, the exhibited thread colours are smoothly deviated and the layered tonal effect emerges under the influence of the surroundings. The small particles of yarn colours on the fabric surface are capable of presenting natural colour mixing. However, since the background is filled with white (Figure 11), the resultant yarn effect is lacking in vividness as cyan, magenta and yellow yarns are mostly presented in chroma difference. Therefore, further optimisation is planned when designing weave patterns by intricate overlapping of colour regions with primary ranges which will be discussed in the next section. 

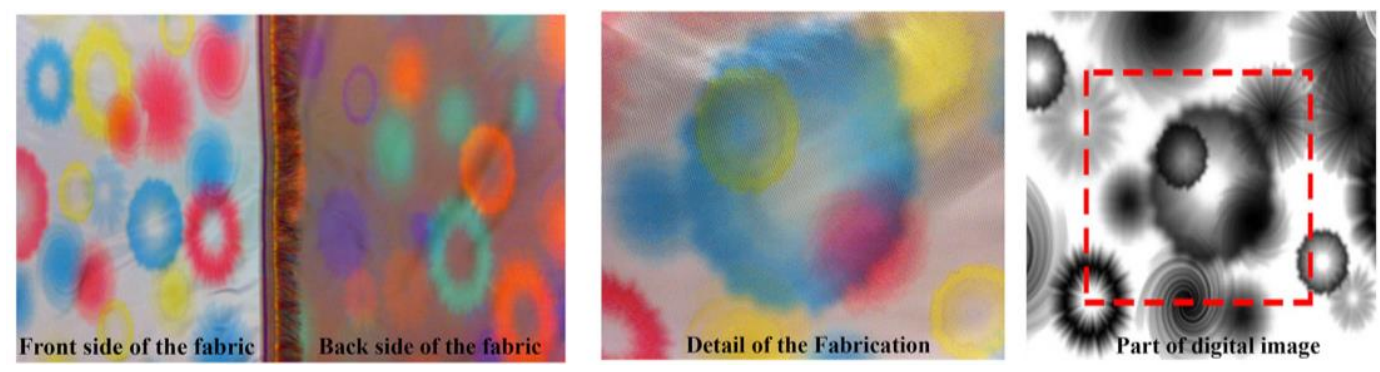

Figure 11. Preliminary experiment for pigment mixing effect

\section{Optimisation of weaving conditions for simulation of pigment mixing effect for}

\section{Jacquard design development}

In this experiment, the sizes of the five weave patterns are designed according to the maximum width of the Jacquard machine $((289 \mathrm{~cm}$ (width) $x 281 \mathrm{~cm}$ (high)) with the intention of producing a fabric in one complete repeat. Five colour patterns (i.e. cyan, magenta, yellow, green and black) are designed to fulfil the weave pattern regions where several colours are commonly shared and placed (Figure 12). In the yarn colour mixing, green shades are simulated with cyan and yellow combinations whilst there is a limit to opaque yarn to present the colours in such brightness ${ }^{11}$. Therefore, one supplementary colour pattern is added to the florescent green yarn to amplify the woven colour effect in addition to the four primaries (i.e. $[\mathrm{C}]+[\mathrm{G}],[\mathrm{M}]+[\mathrm{G}],[\mathrm{Y}]+[\mathrm{G}]$ and $[\mathrm{K}]+[\mathrm{G}]$ ). In Photoshop CS6, the operations known as 'blurring' processed by low-pass or filtering are provided. As the function are equipped with several different options to iron out significant grey-level variances between pixels, weave pattern conditions can be modified and restructured in different ways. In this experiment, the Lens Blur filter which provides blurring options like camera lenses is used to smooth the overall greyscale values of each weave pattern. This filter proposes the amount of blurring radius from 0 to $100^{12}$ and the five weave patterns shown in Figure 12 are generally smoothed by applying 30-radius value. When selecting a proper shaded weave, the greyscale 
value becomes the standard for creating weave colours. In the extra weft mode of the Jacquard CAD system (Arahne), single weave structures are combined and weaving data are formed for fabrication.

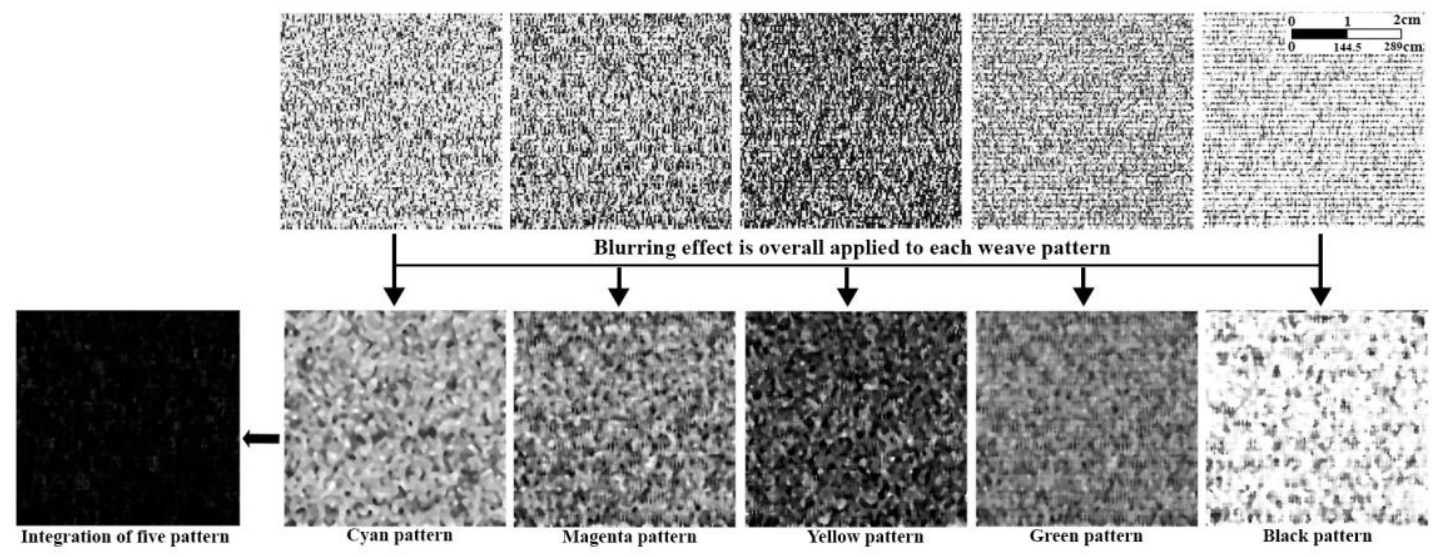

Figure 12. Optimised weave patterns for simulation of pigment mixing effect

In the preliminary fabrication, the vividness of fabric colours is locked as the background is filled with white. Therefore, the five colour patterns are designed to comprise primary ranges (Figure 12) to induce as much mixing effect as possible. In the weave structure design, a 20thread twill weave structure is used for building two sets of shaded weave series. Compared to the 16-thread, 69 varieties are conceived by applying four interlacements. As a result, the greyscale variety of each weave pattern is less reduced and shades are mostly produced in the weave structure combinations more than in the 16-thread sateen weave series. Figure 13 shows the two shaded weave series applied to the actual sample production in detail.
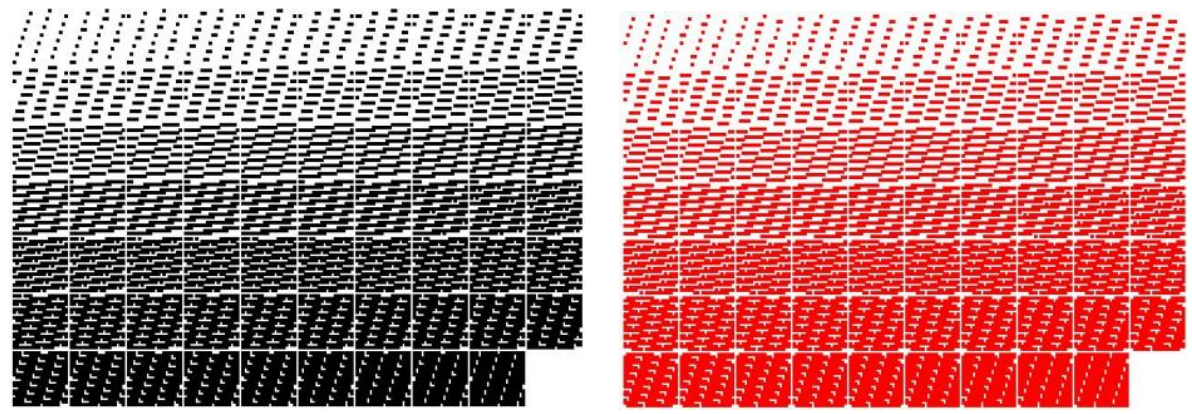
Figure 13. First (left) and second (right) shaded weave series in 20-thread twill weave

In order to maintain proper fabric firmness, the density applied to the 5 filling yarns is higher $(1280$ picks $/ 10 \mathrm{~cm})$ than that to the two filling yarns $(512$ picks $/ 10 \mathrm{~cm})$ of the weave sample. As usage of fine yarn in the weft is proved beneficial to a smooth presentation of yarn colours, the 50-denier polyester yarn is interwoven with the 100-denier off-white warp. The weaving specifications applied in the fabric production are shown in Table 2.

Table 2. Weaving specifications of a new Jacquard design development

\begin{tabular}{|c|c|c|}
\hline Composition & Weft & Warp \\
\hline Material & $100 \%$ polyester & $100 \%$ polyester \\
\hline Thread colour & Cyan/magenta/yellow/black/green & Off-white \\
\hline Yarn count & 50 denier & 100 denier \\
\hline Yarn type & Multifilament & Multifilament \\
\hline $\mathbf{5}$ filling density & 1280 picks/10cm & 472 ends/10cm \\
\hline Jacquard machine & Stäubli JC6 \\
\hline Total hooks & 8192 \\
\hline Pattern repeat & 289 cm (width) x $281 \mathrm{~cm}$ (height) \\
\hline Weave size & $20-$ thread twill \\
\hline Shaded weave variety & \multicolumn{2}{|c|}{69} \\
\hline Software applied & Photoshop CS6/Arahne CAD \\
\hline
\end{tabular}
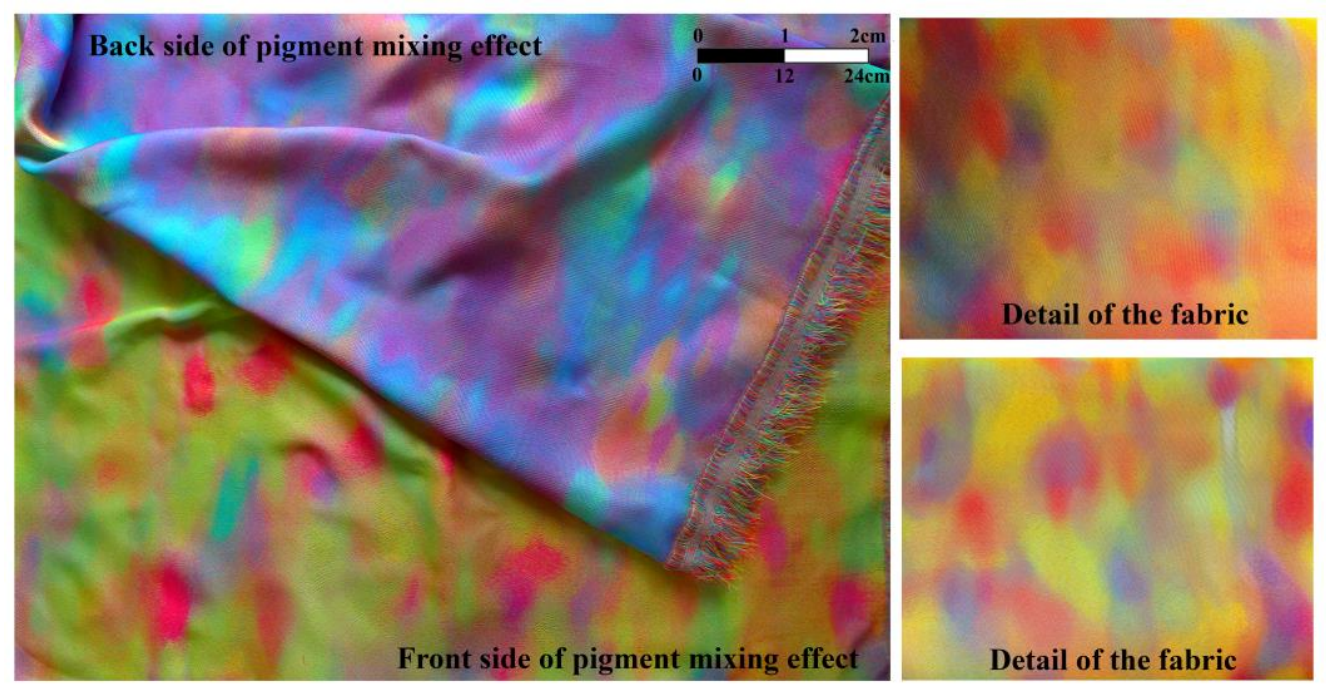

Figure 14. Simulated pigment mixing effect in woven Jacquard textile 
Figure 14 shows that the exhibited yarn colours of the resultant fabric bear a great similarity to the pigment mixing effect. In using opaque and non-blendable yarn material, the effect can be simulated through delicate management of yarn colours. As small particles of exhibited yarn colours reflect varied intensities of light from the fabric surface, weave colours are created and perceived in a delicate combination of yarn colours ${ }^{13}$.

Table 3. Physical characteristics of the fabric

\begin{tabular}{|l|c|c|}
\hline & Weight $\left(\mathbf{g} / \mathbf{c m}^{\mathbf{2})}\right.$ & Thickness of the fabric $(\mathbf{m m})$ \\
\hline & $145.2 \mathrm{~g} / \mathrm{cm}^{2}$ & $0.6 \mathrm{~mm}$ \\
\hline Warp & Shear property of the fabric & Stiffness of the fabric \\
\hline Weft & 0.30 & 0.05 \\
\hline
\end{tabular}

The physical characteristics of the fabric are inspected for fabric weight, fabric thickness, shear property and fabric stiffness. The shear and stiffness tests are carried out three times in standard conditions (a temperature of $20 \pm 1{ }^{\circ} \mathrm{C}$ and a relative humidity of $65 \pm 5 \%$ ) and the average is presented in Table 3. The shearing properties are measured by the KES-FB1 shear tester (Katotech Co., LTD) which determines the fabric formability for a smooth garmentmaking process ${ }^{14}$. Under the irregular interlacements given by twill-based shaded weave combinations, the shear properties of the warp and weft turn out to be similar. In contrast, the fabric stiffness measured by the KES-FB2 shear tester (Katotech Co., LTD) shows some variation between the warp and weft. As the applied densities have a great disparity between warp $(472$ ends $/ 10 \mathrm{~cm})$ and weft $(1280$ picks $/ 10 \mathrm{~cm})$, the weft is much stiffer than the warp.

\section{Conclusion}

The gamut of CMYK yarn colours can be expanded via the shaded weave format. Regarding 
the technical limitations of modern digital weaving, weft colours are the key to realise artwork colours and therefore, CMYK weave colours are examined for their capability of gamut expansion. In using non-transparent and non-blendable yarn material, CMY yarn combinations show their hue changes while weave colours juxtaposed with black present varied levels of chroma. A great similarity to the pigment mixing effect is mimicked in their pair combination. In manipulation of digital weave patterns, further experiments are conducted for the presentation of novel woven colours. Extreme variation in greyscales is ironed out to exhibit filling yarn floats in their gradual lengthened order. The amplified pigment mixing effect through overlapping of colour regions suggests new digital Jacquard design. As modern digital Jacquard weaving has focused on efficiency and convenience of production, many artistic values of weaving have vanished. However, consistent development through understanding of weave structure design, weave pattern design and colour systems can overcome the technical limitations of modern weaving and unleash great potential for digital Jacquard.

\section{Funding}

This work was supported by the General Research Fund of the Hong Kong Research Grant Council (project code PolyU 5274/09E) and the Hong Kong Polytechnic University (project code B-Q17G).

\section{References}

[1] Watson W and Grosicki Z. Watson's advanced textile design: compound woven structures, 4th edn. Newnes-Butterworths: London/Boston: MA, 1977, pp.13-25.

[2] Kaiser L. Jacquard weaving coloured material. Patent No DE4438535A1, German, 1996.

[3] Watson W and Grosicki Z. Watson's textile design and colour: elementary weaves and 
figured fabrics, 7th ed. Newnes-Butterworths: London, 1975, pp.221-225.

[4] Ng F and Zhou J. Innovative jacquard textile design using digital technologies. Woodhead Publishing Series in Textiles. Burlington: Elsevier Science, 2013, pp.81-106.

[5] Ng MCF and Zhou J. Full-colour compound structure for digital jacquard fabric design. Journal of the Textile Institute 2010;101: pp.52-57.

[6] Berns RS, Billmeyer FW and Saltzman M. Billmeyer and Saltzman's principles of color technology, 3rd edn. Wiley:New York, 2000, pp.151-172.

[7] Ng MCF and Zhou J. Innovative layered-combination mode for digital jacquard fabric design. Textile Research Journal 2009; 79(8): pp.737-743.

[8] Kim KR, Ng F, Zhou J and Hu J. Gradient colour deviation in woven Textiles to correspond to pictorial images in diversity, International Journal of Fashion Design, Technology and Education 2015; 9(1): pp.32-40.

[9] Kendra E and The Clock Against (Firm). Colour companion for the digital artist. Pearson/Prentice Hall, NJ: Upper Saddle River, 2004, pp.19-39.

[10] Zhou J. Reinventing jacquard textile design via the deployment of digitisation technology towards innovative ends. Hong Kong: Institute of Textiles \& Clothing, The Hong Kong Polytechnic University. 2014, pp.45- 94, 154- 159.

[11] Mathur K. Colour prediction model for jacquard tapestry woven fabrics. USA: Fiber and Polymer Science, North Carolina, 2007, pp.48-55.

[12] Elaine W and Peter L. Photoshop CS6: For Windows and Macintosh, Peachpit Press, Berkeley, CA, 2012, pp.309-324.

[13] Dimitrovski K. and Gabrijelcic H. Correction of colour values of woven fabric using changes to constructional parameters. AUTEX Research Journal 2004, 4(4), pp.187-193.

[14] Kyoung Ok K and Masayuki T. Effects of Adhesive Agent on Shear Stiffness of Fabrics Bonded with Adhesive Interlining, Journal of Fiber Bioengineering \& Informatics 2012 5:2 
pp.151-162

\section{Appendix}

Table 4. Measurement data of warp and weft yarn colours

\begin{tabular}{|l|c|c|c|c|c|}
\hline & Warp & \multicolumn{4}{|c|}{ Filling } \\
\hline & Off-white & Cyan & Magenta & Yellow & Black \\
\hline $\mathbf{L}^{*}$ & 86.491 & 56.154 & 49.253 & 83.525 & 18.74 \\
\hline $\mathbf{a}^{*}$ & -0.744 & -25.007 & 63.574 & -0.734 & 1.25 \\
\hline $\mathbf{b}^{*}$ & 0.983 & -25.82 & 2.636 & 73.284 & -1.356 \\
\hline
\end{tabular}

Table 5. $\mathrm{L}^{*}, \mathrm{a}^{*}$ and $\mathrm{b}^{*}$ data of $\mathrm{C} / \mathrm{M}$ and $\mathrm{M} / \mathrm{Y}$ mixture swatches

\begin{tabular}{|c|c|c|c|c|c|c|c|}
\hline & $\mathbf{L}^{*}$ & $a^{*}$ & $\mathbf{b}^{*}$ & & $\mathbf{L}^{*}$ & $\mathbf{a}^{*}$ & $\mathbf{b}^{*}$ \\
\hline C/M 1 & 62.24 & -5.52 & -16.60 & M/Y 1 & 58.35 & 54.64 & 11.13 \\
\hline $\mathrm{C} / \mathrm{M} 2$ & 61.28 & -3.99 & -17.09 & $\mathrm{M} / \mathrm{Y} 2$ & 58.32 & 54.41 & 12.24 \\
\hline C/M 3 & 56.67 & -7.65 & -19.66 & $\mathrm{M} / \mathrm{Y} 3$ & 59.13 & 52.70 & 14.28 \\
\hline $\mathrm{C} / \mathrm{M} 4$ & 53.99 & 1.02 & -19.18 & $\mathrm{M} / \mathrm{Y} 4$ & 60.13 & 48.72 & 19.91 \\
\hline C/M 5 & 52.72 & 5.35 & -18.79 & $\mathrm{M} / \mathrm{Y} 5$ & 61.12 & 46.09 & 23.69 \\
\hline C/M 6 & 52.38 & 7.93 & -18.52 & M/Y 6 & 61.62 & 44.65 & 24.82 \\
\hline C/M 7 & 51.25 & 13.43 & -17.92 & $\mathrm{M} / \mathrm{Y} 7$ & 62.33 & 42.61 & 28.51 \\
\hline C/M 8 & 49.33 & 20.59 & -17.41 & $\mathrm{M} / \mathrm{Y} 8$ & 63.24 & 39.60 & 32.09 \\
\hline C/M 9 & 49.51 & 23.17 & -16.62 & $\mathrm{M} / \mathrm{Y} 9$ & 65.80 & 33.72 & 35.07 \\
\hline C/M 10 & 49.44 & 27.55 & -15.51 & $\mathrm{M} / \mathrm{Y} 10$ & 67.04 & 30.18 & 36.48 \\
\hline C/M 11 & 49.24 & 29.39 & -14.83 & $\mathrm{M} / \mathrm{Y} 11$ & 67.89 & 27.87 & 39.18 \\
\hline C/M 12 & 49.42 & 32.98 & -13.42 & $\mathrm{M} / \mathrm{Y} 12$ & 69.26 & 24.53 & 40.78 \\
\hline C/M 13 & 50.09 & 38.91 & -10.93 & M/Y 13 & 72.73 & 17.01 & 44.87 \\
\hline C/M 14 & 50.59 & 41.58 & -10.15 & M/Y 14 & 74.60 & 16.20 & 38.60 \\
\hline C/M 15 & 51.23 & 42.81 & -9.22 & M/Y 15 & 75.67 & 14.43 & 39.00 \\
\hline
\end{tabular}

* $\mathrm{C}=$ cyan, $\mathrm{M}=$ magenta and $\mathrm{Y}=$ yellow

Table 6. $\mathrm{L}^{*}$, $\mathrm{a}^{*}$ and $\mathrm{b}^{*}$ data of $\mathrm{C} / \mathrm{Y}$ and $\mathrm{C} / \mathrm{K}$ colour swatches

\begin{tabular}{|c|c|c|c|c|c|c|c|}
\hline & $\mathbf{L} *$ & $\mathbf{a}^{*}$ & $\mathbf{b}^{*}$ & & $\mathbf{L}^{*}$ & $\mathbf{a}^{*}$ & $\mathbf{b}^{*}$ \\
\hline $\mathrm{C} / \mathrm{Y} 1$ & 65.20 & -25.84 & -7.75 & $\mathrm{C} / \mathrm{K} 1$ & 56.37 & -18.65 & -18.20 \\
\hline $\mathrm{C} / \mathrm{Y} 2$ & 65.39 & -25.96 & -5.69 & $\mathrm{C} / \mathrm{K} 2$ & 55.26 & -18.17 & -17.67 \\
\hline C/Y 3 & 65.20 & -26.29 & -3.93 & $\mathrm{C} / \mathrm{K} 3$ & 53.39 & -17.22 & -16.89 \\
\hline $\mathrm{C} / \mathrm{Y} 4$ & 65.40 & -26.31 & 2.24 & $\mathrm{C} / \mathrm{K} 4$ & 49.48 & -16.20 & -15.81 \\
\hline C/Y 5 & 65.81 & -26.27 & 6.64 & $\mathrm{C} / \mathrm{K} 5$ & 46.58 & -15.57 & -15.16 \\
\hline C/Y 6 & 66.02 & -26.33 & 7.88 & $\mathrm{C} / \mathrm{K} 6$ & 45.92 & -15.10 & -14.87 \\
\hline $\mathrm{C} / \mathrm{Y} 7$ & 66.70 & -25.76 & 12.37 & $\mathrm{C} / \mathrm{K} 7$ & 43.44 & -14.08 & -13.98 \\
\hline C/Y 8 & 67.03 & -25.37 & 15.74 & $\mathrm{C} / \mathrm{K} 8$ & 39.47 & -12.50 & -12.71 \\
\hline $\mathrm{C} / \mathrm{Y} 9$ & 68.44 & -22.50 & 21.32 & $\mathrm{C} / \mathrm{K} 9$ & 38.13 & -10.80 & -11.47 \\
\hline $\mathrm{C} / \mathrm{Y} 10$ & 69.28 & -20.96 & 25.19 & $\mathrm{C} / \mathrm{K} 10$ & 35.93 & -9.187 & -10.13 \\
\hline $\mathrm{C} / \mathrm{Y} 11$ & 69.54 & -20.33 & 27.88 & $\mathrm{C} / \mathrm{K} 11$ & 34.89 & -8.52 & -9.61 \\
\hline $\mathrm{C} / \mathrm{Y} 12$ & 71.16 & -18.35 & 31.42 & $\mathrm{C} / \mathrm{K} 12$ & 34.82 & -6.78 & -8.17 \\
\hline $\mathrm{C} / \mathrm{Y} 13$ & 72.94 & -15.48 & 38.82 & C/K 13 & 32.90 & -3.38 & -5.14 \\
\hline C/Y 14 & 75.90 & -14.42 & 33.04 & C/K 14 & 32.09 & -2.70 & -4.53 \\
\hline C/Y 15 & 76.73 & -13.83 & 35.52 & $\mathrm{C} / \mathrm{K} 15$ & 31.57 & -2.05 & -3.86 \\
\hline
\end{tabular}

\footnotetext{
$* \mathrm{C}=$ cyan, $\mathrm{Y}=$ yellow and $\mathrm{K}=$ black
} 
Table 7. $\mathrm{L}^{*}, \mathrm{a}^{*}$ and $\mathrm{b}^{*}$ data of $\mathrm{M} / \mathrm{K}$ and $\mathrm{Y} / \mathrm{K}$ mixture swatches

\begin{tabular}{|c|c|c|c|c|c|c|c|}
\hline & $\mathbf{L}^{*}$ & $\mathbf{a}^{*}$ & $\mathbf{b}^{*}$ & & $\mathbf{L}^{*}$ & $\mathbf{a}^{*}$ & \\
\hline M/K 1 & 47.61 & 44.82 & -4.25 & Y/K 1 & 69.58 & -5.88 \\
\hline M/K 2 & 47.03 & 42.35 & -4.28 & Y/K 2 & 67.78 & -5.70 \\
\hline M/K 3 & 45.65 & 41.19 & -4.27 & Y/K 3 & 65.76 & -5.53 \\
\hline M/K 4 & 42.07 & 38.39 & -3.79 & Y/K 4 & 61.16 & -5.04 \\
\hline M/K 5 & 39.47 & 37.22 & -3.84 & Y/K 5 & 57.83 & -4.99 \\
\hline M/K 6 & 38.97 & 36.05 & -3.90 & Y/K 6 & 56.40 & -4.76 \\
\hline M/K 7 & 37.27 & 34.51 & -3.83 & Y/K 7 & 54.12 & -4.63 \\
\hline M/K 8 & 34.76 & 32.37 & -3.72 & Y/K 8 & 50.62 & -4.24 \\
\hline M/K 9 & 34.38 & 28.14 & -3.10 & Y/K 9 & 47.88 & -3.63 \\
\hline M/K 10 & 33.66 & 24.00 & -2.67 & Y/K 10 & 44.93 & -3.05 \\
\hline M/K 11 & 32.43 & 22.33 & -2.59 & Y/K 11 & 43.52 & -2.82 \\
\hline M/K 12 & 32.76 & 18.45 & -2.19 & Y/K 12 & 41.41 & -2.13 \\
\hline M/K 13 & 31.37 & 9.47 & -1.37 & Y/K 13 & 36.01 & -0.70 \\
\hline M/K 14 & 40.11 & 11.35 & -1.21 & Y/K 14 & 45.62 & -0.57 \\
\hline M/K 15 & 40.42 & 10.02 & -1.10 & Y/K 15 & 44.85 & -0.11 \\
\hline
\end{tabular}

* $\mathrm{M}=$ magenta, $\mathrm{Y}=$ yellow and $\mathrm{K}=$ black 